\title{
Effectiveness of Ionic Correction along with Conventional Physiotherapy in Patients Recovering from Stroke: A Case Study
}

\author{
Charan Gutala1, Daddy Kabamba Numbi1,2, Amirali Diama1,3, Guy Bumoko Makila1,4, \\ Samsuddin Amlani' ${ }^{5}$ Kanjiyani Samsuddin Amirali'5, Ashikali Amirali Panjwani ${ }^{5}$ \\ ${ }^{1}$ Department of Pain \& Rehabilitation, Centre Hospitalier International de Kinshasa, Kinshasa, Democratic Republic of Congo \\ ${ }^{2}$ Department of Clinical Biology, Centre Hospitalier International de Kinshasa, University of Kinshasa, Kinshasa, \\ Democratic Republic of Congo \\ ${ }^{3}$ Department of General Medicine, Centre Hospitalier International de Kinshasa, Kinshasa, Democratic Republic of Congo \\ ${ }^{4}$ Department of Neuropsychiatry, Centre Hospitalier International de Kinshasa, Kinshasa, Democratic Republic of Congo \\ ${ }^{5}$ Department of Administration, Centre Hospitalier International de Kinshasa, Kinshasa, Democratic Republic of Congo \\ Email: charancharan61@gmail.com
}

How to cite this paper: Gutala, C., Numbi, D.K., Diama, A., Makila, G.B., Amlani, S., Amirali, K.S. and Panjwani, A.A. (2020) Effectiveness of Ionic Correction along with Conventional Physiotherapy in $\mathrm{Pa}$ tients Recovering from Stroke: A Case Study. Open Journal of Therapy and Rehabilitation, 8, 153-163.

https://doi.org/10.4236/ojtr.2020.84014

Received: September 20, 2020

Accepted: November 2, 2020

Published: November 5, 2020

Copyright $\odot 2020$ by author(s) and Scientific Research Publishing Inc. This work is licensed under the Creative Commons Attribution International License (CC BY 4.0).

http://creativecommons.org/licenses/by/4.0/ (c) (i) Open Access

\begin{abstract}
Background and Aims: Brain damage caused by stroke is associated with sensorimotor and/or cognitive impairment, depending on area of brain affected and the severity of attack. The aims of this study were to show the importance of physiotherapy associated with electrolyte and mineral balance through diet correction in patients recovering from stroke. Methods: This is a follow-up study of two patients with stroke followed at Kinshasa International Hospital Center during period from May 16 to July 1, 2020. The first had received physiotherapy with foods for correction of the existing ionic and mineral deficiency and the second had only received pharmacological management with conservative physiotherapy without making a change in diet. Clinical and electrolyte monitoring was performed at regular intervals in both patients. The variables of interest evaluated in both patients were FIM, MOTOR/SENSORY and Ionic balance. Results: The parameters of FIM, motors and sensory functions were improved during follow-up, however they remained disturbed in the control. $\mathrm{Na}^{+}, \mathrm{Cl}^{-}, \mathrm{K}^{+}, \mathrm{Ca}^{2+}$, and ionic $\mathrm{Ca}^{+}$improved from intake to discharge. The biological parameters deteriorated during follow-up in the control. At Day 1 , only $\mathrm{K}^{+}$which was higher in the control than the case. At discharge, a significant drop in $\mathrm{K}^{+}$control was noted (4.1 vs 3.4); of $\mathrm{Na}^{+}$(142 vs 125) and of $\mathrm{Cl}^{-}$(109 vs 85). Conclusion: The results show that ionic balance by diet correction associated with physiotherapy is more effective than conventional physiotherapy associated with pharmacological management.
\end{abstract}




\section{Keywords}

Stroke, Diet Correction, Physiotherapy, Ionic Balance, CHIK

\section{Introduction}

Cerebrovascular accident (stroke) is defined according to the World Health Organization as "a sudden deficit of focal brain function with no apparent cause other than a vascular cause" [1]. It is the third leading cause of death and the leading cause of disability in the world [2]. Brain injury is associated with sensorimotor and/or cognitive disorders, depending on the area of the brain affected and the severity of the injury [3] [4]. Initially, these are non-permanent deficits, which tend to decline over time. However, it appears that only one in ten people recover all of their functions, and $40 \%$ preserve difficulties in the activities of daily living [5]. Following the accident, three phases can be distinguished: the acute phase which concerns the first 14 days, the subacute phase, from day 14 to month 6 and the chronic phase, after 6 months [6]. The care pathways differ from patient to patient, but hospital treatment from the first symptoms is vitally important. A multidisciplinary care is then put in place, combining medical care and physiotherapy [7]. The hospitalization time is intended to be as short as possible, in favor of a return home, or a structure suitable for physiotherapy and functional recovery [7]. Indeed, the hospital is a gateway for $30 \%$ of patients, who require a transfer to Follow-up Care and Rehabilitation [8]. Physiotherapy associated with diet in the management of stroke is a controversial topic in the literature. No study has shown its benefit in the management of stroke in hospitals. In this study, the hypothesis is that physiotherapy associated with electrolyte balance through diet correction is much more effective than simple conventional physiotherapy combined with pharmacological management for the patient recovering from stroke could be demonstrated. It is in this context that we intervened with the two patients suffering from a documented stroke. The aim was to demonstrate the importance of physiotherapy associated with electrolyte and mineral balance through diet correction in patients recovering from stroke.

\section{Patients and Methods}

This is a case follow-up study carried out on 2 patients at the Center Hospitalier International de Kinshasa during the period from May 16 to July 1, 2020. Two patients who presented a stroke were included after their informed consent and concomitant follow-up during their hospitalization. The first patient had received physiotherapy combined with foods that can correct the existing ionic and mineral deficiency and the second had only received pharmacological management combined with conservative physiotherapy without changing the diet. During their follow-up during hospitalization, clinical and electrolyte monitoring was performed at regular intervals in both patients. The variables of interest 
evaluated in both patients were FIM, MOTOR/SENSORY and Ionic balance.

The Tools used to assess the improvements in our comparative subjects are:

1) Functional independence measure Scale (FIM): To Assess the functional independence achieved by patients at different stages of the Treatment \& Management [9] [10].

These are the components involved in this study:

Functional Independence Measure (FIM) Instrument

\begin{tabular}{l}
\hline ADMISSION DISCHARGE \\
Aelf-Care \\
A. Eating \\
B. Grooming \\
C. Bathing \\
D. Dressing-Upper Body \\
F. Toileting \\
Sphincter Control \\
G. Blandder Management \\
H. Bwel Management \\
Transfers \\
I. Bed, Chair, Wheelchair \\
J. Toilet \\
K. Tub, Shower \\
Locomotion \\
L. Walk/wheelchair \\
M. Stairs \\
Motor Subtotal Score \\
Communication \\
N. Comprehension \\
O. Expression \\
Pocial Cognition \\
Tot. Social Interaction
\end{tabular}

Independent

7 Complete Independence (Timely, Safely)

NO HELPER

6 Modifier Independence (Device)

Modified Dependence

LEVELS

5 Supervision $($ Subject $=100 \%+)$

4 Minimal Assist (Subject $=75 \%+$ )

3 Moderate Assist (Subject $=50 \%+$ )

Complete Dependence

2 Maximal Assist (Subject $=25 \%+$ )

1 Total Assist (Subject $=$ less than 25\%)

Note : Leave no blanks. Enter 1 if patient is not testable due risk. 
2) Manual Muscle Testing (MMT): It's an internationally renowed Scale to know the muscle strength manually (Table 1).

3) DTR (Deep Tendon Reflexes): It indicates the status of reflex recovery of nerve at different stages of the treatment [11].

Check the tendon reflexes using impulses from a reflex hammer to stretch the muscle and tendon. The limbs should be in a relaxed and symmetric position, since these factors can influence reflex amplitude. As in muscle strength testing, it is important to compare each reflex immediately with its contralateral counterpart so that any asymmetric reinforcement procedures. For example, have the patient gently contract the muscle being tested by raising the limb very slightly, or have them when the reflex is tested. When reflexes are very brisk, clonus is sometimes seen. This is a repetitive vibratory contraction of the muscle that occurs in response to muscle and tendon stretch. Deep tendon reflexes are often rated according to the following scale:

- 0 : absent reflex.

- $1^{*}$ : trace, or seen only with reinforcement.

- $2^{*}$ : normal.

- $3^{*}$ : brisk.

- $4^{*}$ : nonsustained clonus (i.e., repetitive vibratory movements).

- $5^{\star}$ : sustained clonus.

Table 1. Components and gradings of this scale are [10].

\begin{tabular}{|c|c|c|c|c|}
\hline \multicolumn{5}{|c|}{ MANUAL MUSCLE TESTING PROCEDURES } \\
\hline \multicolumn{5}{|c|}{ Key to Muscle Grading } \\
\hline & Function of the Muscle & \multicolumn{3}{|c|}{ Grade } \\
\hline \multirow{2}{*}{$\begin{array}{c}\text { No } \\
\text { Movement }\end{array}$} & No contractions felt in the muscle & 0 & 0 & zero \\
\hline & $\begin{array}{l}\text { Tendon becomes prominent or feeble contraction felt in } \\
\text { the muscle, but no visible movement of the part }\end{array}$ & $\mathrm{T}$ & 1 & Trace \\
\hline \multirow{5}{*}{$\begin{array}{c}\text { Test } \\
\text { Movement }\end{array}$} & MOVEMENT IN HORIZONTAL PLANE & & & \\
\hline & Moves through partial range of motion & 1 & $2-$ & Poor- \\
\hline & Moves through complete range of motion & 2 & 2 & Poor \\
\hline & ANTIGRAVITY POSITION & \multirow{2}{*}{3} & \multirow{2}{*}{$2+$} & \\
\hline & Moves through partial range of motion & & & \\
\hline \multirow{7}{*}{$\begin{array}{c}\text { Test } \\
\text { Position }\end{array}$} & Gradual release from test position & 4 & $3-$ & Fair- \\
\hline & Holds test position (no added pressure) & 5 & 3 & Fair \\
\hline & Holds test position against slight pressure & 6 & $3+$ & Fair+ \\
\hline & Holds test position against slight to moderate pressure & 7 & $4-$ & Good- \\
\hline & Holds test position against moderate pressure & 8 & 4 & Good \\
\hline & Holds test position against moderate strong pressure & 9 & $4+$ & Good+ \\
\hline & Holds test position against strong pressure & 10 & 5 & Normal \\
\hline
\end{tabular}

Modified from 1993 Florence P. kendal author grants permission to reproduce this chart. 
Deep tendon reflexes are normal if they are $1^{*}, 2^{*}$, or $3^{*}$ unless they are asymmetric or there is a dramatic difference between the arms and the legs. Reflexes rated as $0,4^{*}, 5^{\star}$ are usually considered abnormal. In addition to clonus, other signs of hyperreflexia include spreading of reflexes to other muscles not directly being tested and crossed adduction of the opposite leg when the medial aspect of the knee is tapping.

4) Blood tests used to compare the ionic deficiencies in the body-ions which are studied are- $\mathrm{Na}^{2+}, \mathrm{K}^{+}, \mathrm{Cl}^{-}, \mathrm{Ca}^{2+}, \mathrm{Ca}^{2+}$ serum

\section{Methods used}

1) Strengthening activities

- active/active assisted exercises to the upper limb and lower limbs.

- active assisted balance and coordination exercises.

- pelvic stability activities.

2) Stretching and positioning activities

- quadriceps and hamstring stretches.

- spastic reflexes corrective posture.

3) Diet counselling \& lifestyle Management-Advised to change the diet and not to eat fried oily foods stuffs \& Non-Vegetarian diet and encouraged to eat more fruits and vegetables.

4) Vitamins and minerals and electrolytes deficiency management

- Given vitD supplements and been advised to maintain salt consumption to $1500 \mathrm{mg} /$ day.

The recommended dose of potassium per day is $4.7 \mathrm{~g}$ according to Ohio State University's Linus Pauling Institute. Oranges are a good source of potassium, providing $237 \mathrm{mg}$ each, and a $6 \mathrm{oz}$. serving of orange juice provides $372 \mathrm{mg}$, according to the Linus Pauling Institute. This is approximately 5 percent of the 4.7 $\mathrm{g}$ of potassium per day recommended for most people.

1 medium size potato contains $925.6 \mathrm{mg}$ of potassium: According to US Food and Drug administration 1 banana contains $450 \mathrm{mg}$ of banana. We advised for case to take daily, 1 or 2 oranges which constitutes-237-474 $\mathrm{mg} \mathrm{K}^{+} / \mathrm{day}$; 1 or 2 potatoes-925.6 - $1851.2 \mathrm{mg} \mathrm{k}^{+} /$day; 2 - 3 bananas-900 - $1350 \mathrm{mg} \mathrm{k}^{+} /$day.

According to the US Food And Drug Administration, the salt limit for people without hypertension is 2300 milligrams per day and the limit for individuals with hypertension is 1500 milligrams per day.

A very low-salt food is considered to be one with less than 35 milligrams of sodium per serving, according to the U.S. Food and Drug Administration [12].

We advised the case to eat $1500 \mathrm{mg}$ of salt per day in addition to the mild quantities of salt found naturally in the foods generally consumed while the control is been deprived of this addition of salt.

\section{Statistical analyzes}

The data obtained were organized and presented in the form of tables and graphs. The chi-square test compared the proportions and Student's $t$ allowed us to compare the electrolyte values of the two patients. The threshold of statistical significance was set at $\mathrm{p}<0.05$. Data were analyzed using MedCal version 9.1 
software. Anonymity, confidentiality and justice were respected during the conduct of this study. Both patients had freely consented to participate in the study.

\section{Results}

Two male patients aged 27 for the first and 42 for the second, were included in this case study. The first was on appropriate diet and physiotherapy and conventional medical management (case) and the second was under conventional pharmacological Management and physiotherapy for stroke. Their data reported during inpatient follow-up are illustrated in the figures and tables below.

\subsection{FIM}

Figure 1 shows that in cases, the FIM improves during follow-up whereas in the control, the FIM is disturbed (decrease) with a statistically significant difference $(\mathrm{p}=0.001)$.

\subsection{Motor/Sensory}

MS (muscle strength-MMT)

In this Figure 2, we note in the case that the parameters of the upper limb increase significantly $(\mathrm{p}<0.001)$ during follow-up, on the other hand in the control, the parameters remain constant.

We also note in this Figure 3 that in the case that the Lower limb parameters increase significantly $(\mathrm{p}<0.001)$ during follow-up, on the other hand in the control, the parameters remain constant without a significant difference during follow-up ( $\mathrm{p}=0.968)$.

In this Table 2, the UPPR LIMB and LOWER limb of Deep tendon reflexes were increased in the case and remained zero or weak in the control throughout follow-up. The same superficial and deep sensation changed from non-sensitive to normal in the case and non-sensitive in the control during the course followed even at the end of the study.

\subsection{Biological Characters}

In the case, $\mathrm{Na}^{+}, \mathrm{Cl}^{-}, \mathrm{K}^{+}, \mathrm{Ca}^{2+}$, and ionic $\mathrm{Ca}^{+}$improved from intake to discharge.

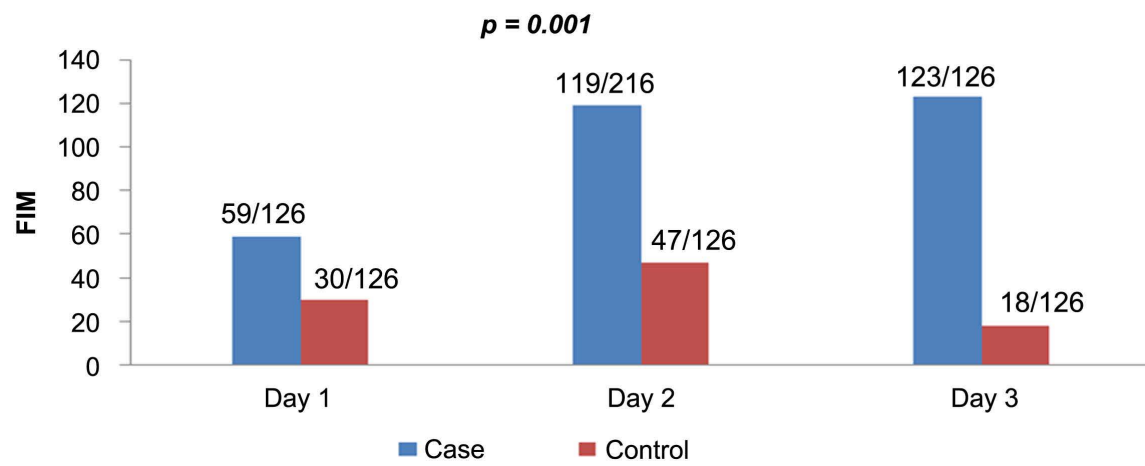

Figure 1. Presentation of FIM of the two patients at admission and at the end of follow-up. 


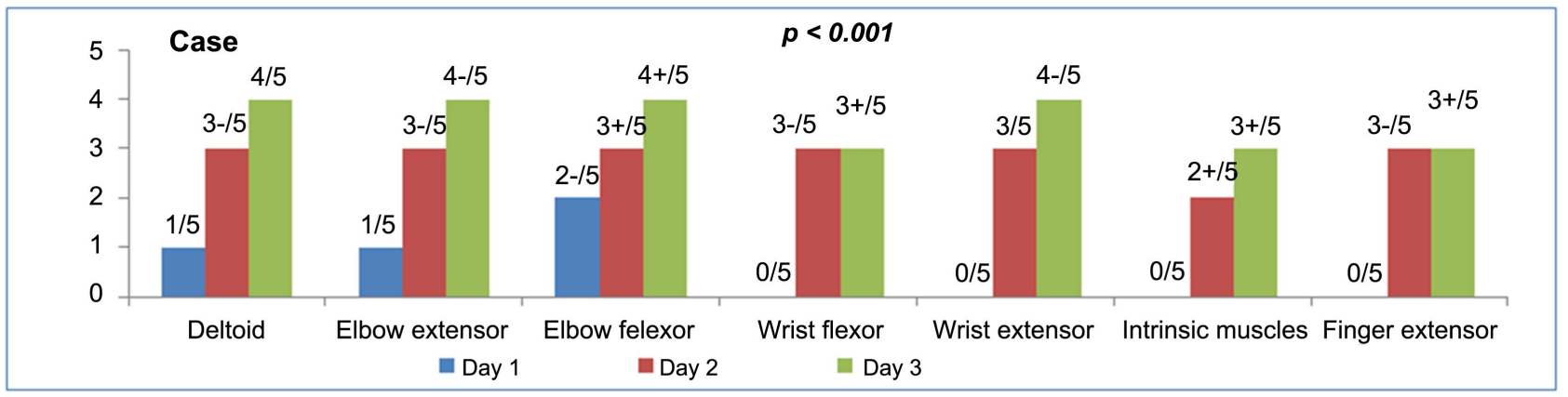

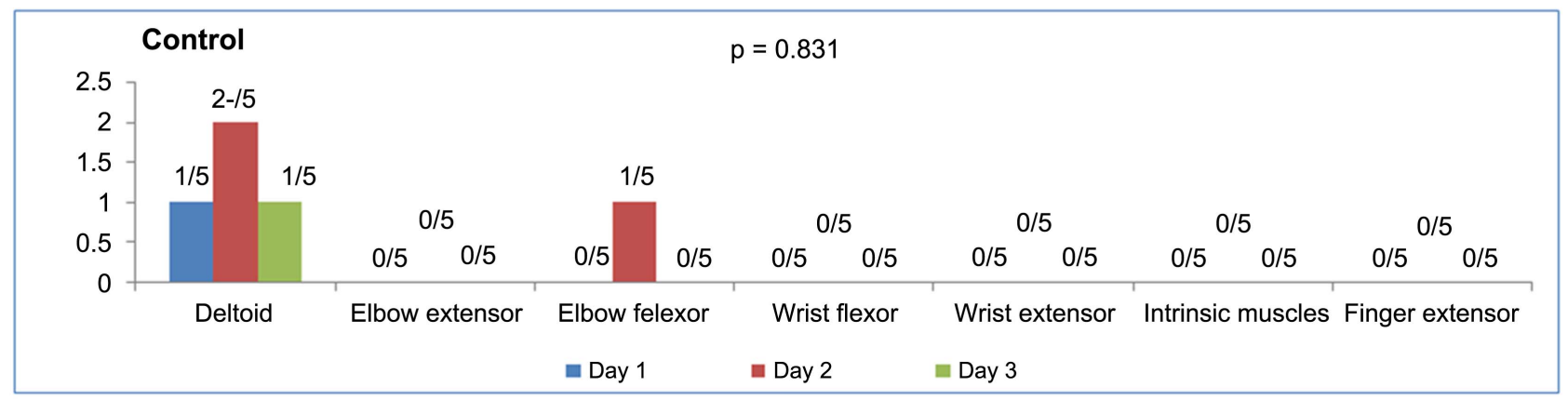

Figure 2. Comparison upper limb between case and control.

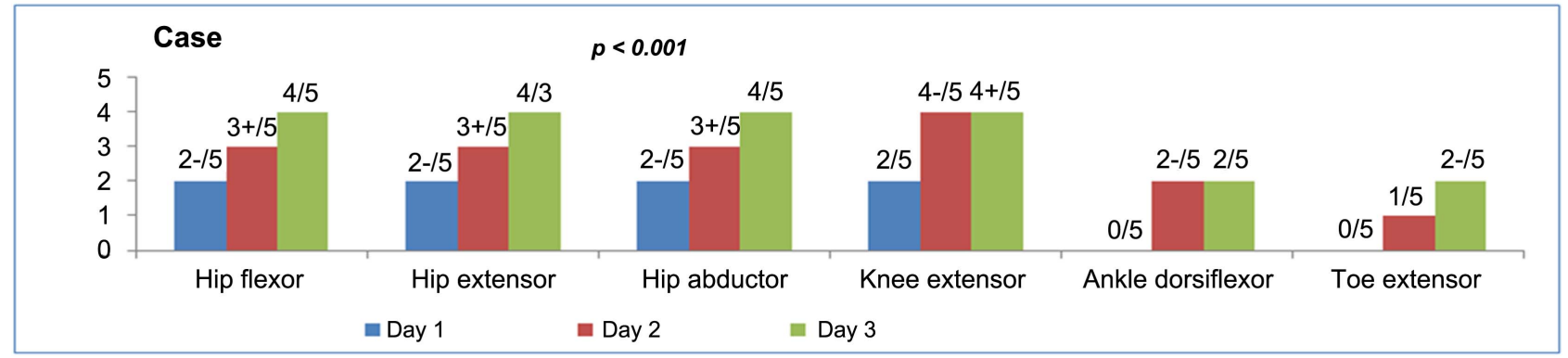

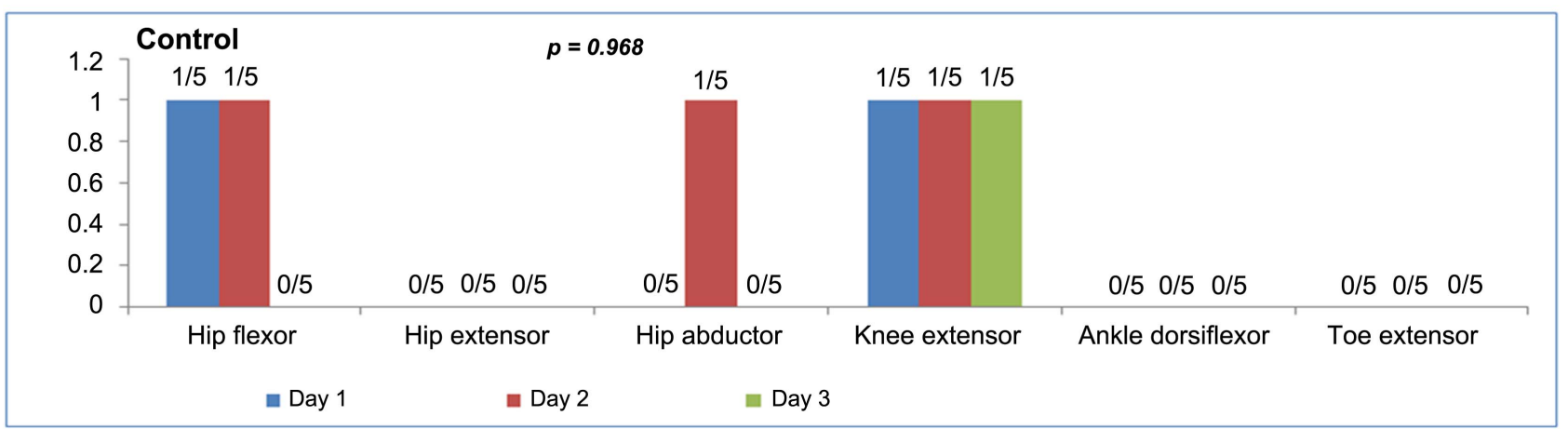

Figure 3. Lower limb comparison between case and control.

On the other hand, these biological parameters deteriorated during follow-up in the control (Table 3).

On admission (Day 1), only the $\mathrm{K}^{+}$which was significantly higher in the control than the case $(\mathrm{p}=0.011)$, the other parameters were not different. At discharge (Day 2), a significant drop in $\mathrm{K}^{+}$control was noted (4.1 vs 3.4, $\mathrm{p}<0.001$ ); of $\mathrm{Na}^{+}$ (142 vs $125, \mathrm{p}=0.031)$ and of $\mathrm{Cl}^{-}(109$ vs $85, \mathrm{p}=0.001)$ (Figure 4). 
Table 2. Other parameters comparison between case and control.

\begin{tabular}{|c|c|c|c|c|c|c|}
\hline \multirow{2}{*}{ parameter } & \multicolumn{3}{|c|}{ Case } & \multicolumn{3}{|c|}{ Control } \\
\hline & Day 1 & Day 2 & Day 3 & Day 1 & Day 2 & Day 3 \\
\hline \multicolumn{7}{|l|}{ Deep tendon reflexes } \\
\hline \multicolumn{7}{|l|}{ UPPR LIMB } \\
\hline Biceps & $1+$ & $2+$ & $2+$ & 0 & 0 & 0 \\
\hline Triceps & $1+$ & $1+$ & $2+$ & 0 & 0 & 0 \\
\hline brachioradialis & $1+$ & $2+$ & $2+$ & 0 & 0 & 0 \\
\hline \multicolumn{7}{|l|}{ Lower limb } \\
\hline Pathellor tendon reflex & $1+$ & $2+$ & $2+$ & 0 & 0 & $1+$ \\
\hline Achillis tendon reflex & $1+$ & $1+$ & $2+$ & 0 & 0 & 0 \\
\hline \multicolumn{7}{|l|}{ Sensation } \\
\hline \multicolumn{7}{|l|}{ superficial sensation } \\
\hline upper limb & $\mathrm{C} 6, \mathrm{C} 7, \mathrm{C} 8$ reduced & C6, C7, C8 normal & Normal & C6, C7, C8 reduced & $\begin{array}{l}\text { C6, C7, improved, } \\
\text { C8 remain same }\end{array}$ & $\begin{array}{l}\text { Due altered } \\
\text { in both upper }\end{array}$ \\
\hline lower limb & L4, L5, S1 Reduced & $\begin{array}{l}\mathrm{L} 4, \mathrm{~L} 5, \mathrm{~S} 1 \\
\text { Improved }\end{array}$ & Normal & L5, S1 reduced & $\begin{array}{l}\text { L5 improved, } \\
\text { S1 same }\end{array}$ & Lower limbs \\
\hline Deep sensation & Intact in both UL \& LL & $\begin{array}{c}\text { Intact in both UL } \\
\text { \& LL }\end{array}$ & Normal & Intact in UL \&LL & Intact in UL & $\begin{array}{c}\text { Due to altered } \\
\text { sensorium }\end{array}$ \\
\hline
\end{tabular}

\section{Day 1}

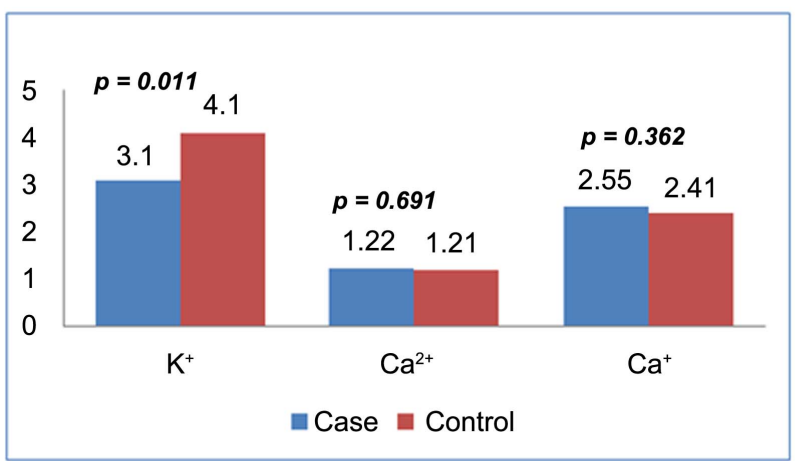

Day 2

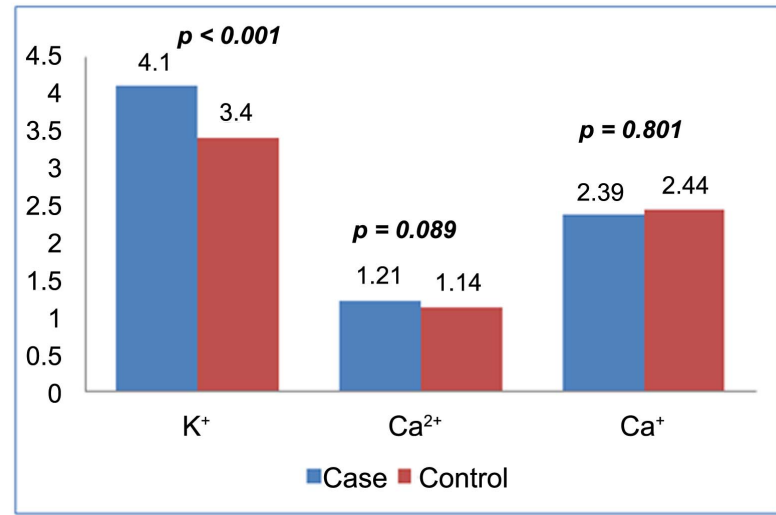

Day 1

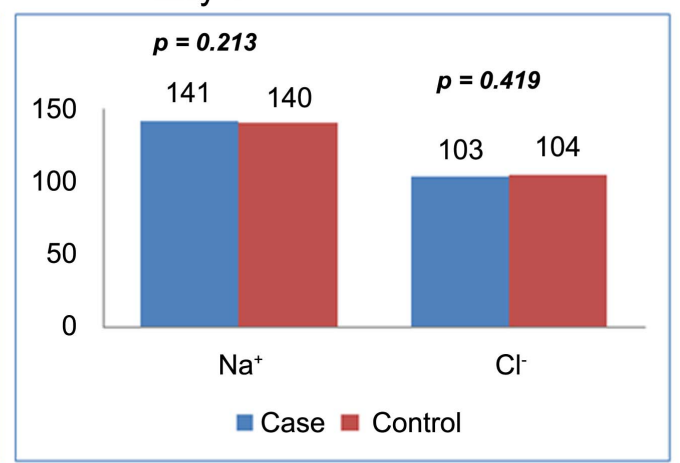

Day 2

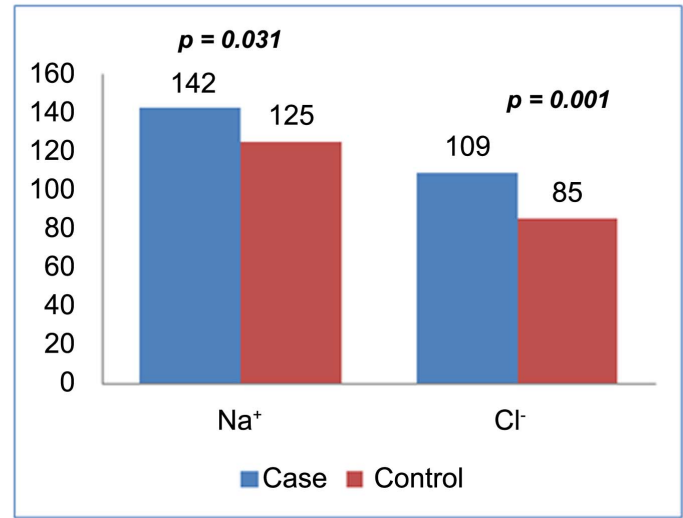

Figure 4. Comparison of electrolytic parameters of cases and control at admission and at Discharge. 
Table 3. Biological characters comparison.

\begin{tabular}{ccccccc}
\hline \multirow{2}{*}{ Parameter } & \multicolumn{3}{c}{ Case } & \multicolumn{3}{c}{ control } \\
\cline { 2 - 7 } & Day 1 & Day 2 & $\mathrm{p}$ & Day 1 & Day 2 & $\mathrm{p}$ \\
\hline $\mathrm{Na}^{+}$ & 141 & 142 & 0.619 & 140 & 125 & $\mathbf{0 . 0 0 6}$ \\
$\mathrm{Cl}^{-}$ & 103 & 109 & 0.091 & 104 & 85 & $<0.001$ \\
$\mathrm{~K}^{+}$ & 3.1 & 4.1 & 0.024 & 4.1 & 3.4 & $\mathbf{0 . 0 1 2}$ \\
$\mathrm{Ca}^{2+}$ & 1.22 & 1.21 & 0.817 & 1.21 & 1.14 & $\mathbf{0 . 0 3 5}$ \\
$\mathrm{Ca}^{+}$ & 2.55 & 2.39 & $\mathbf{0 . 0 4 3}$ & 2.41 & 2.44 & 0.337 \\
\hline
\end{tabular}

\section{Discussion}

Our brain is connected to the rest of the organs and muscles in our body. For example; when our hand moves, the brain sends signals through nerve cells to the muscles in the hand to contract. Nerve cells send out many electrical impulses telling the muscles of the hands to contract. These electrical impulses in nerve cells are known as the action potential. The action potential results from the concentration gradient of the ions $\left(\mathrm{Na}^{+}, \mathrm{K}^{+}\right.$or $\left.\mathrm{Cl}^{-}\right)$. The three main events triggering an action potential are: depolarization, repolarization and hyperpolarization [12]. During depolarization, the doors of $\mathrm{Na}+$ ions are opened. It brings an influx of $\mathrm{Na}^{+}$ions into the cell and as a result the neuronal cell is depolarized. The action potential passes through the axons. Upon repolarization, the cell returns to the resting membrane potential by stopping the influx of $\mathrm{Na}^{+}$ions, but the $\mathrm{K}^{+}$ions exit the neuronal cell due to the opening of $\mathrm{k}^{+}$ion gates during repolarization. When the action potential crosses $\mathrm{K}^{+}$channels for too long, the neuron loses more $\mathrm{K}^{+}$ions. This results in hyperpolarization of the neuronal cell (more negative than the resting membrane potential). Hyperpolarization is normally due to the efflux of $\mathrm{K}^{+}$ions from the $\mathrm{K}^{+}$channels or the influx of $\mathrm{Cl}^{-}$ ions from the $\mathrm{Cl}$ channels [12]. Through this study, we even saw the importance of $\mathrm{Cl}^{-}$ions as an alternative to $\mathrm{K}^{+}$ions in returning the membrane potential to its resting state and thus helping to return the hyperpolarized nerve to its resting membrane potential so that it becomes ready for its next cycle of depolarization and muscle contraction. So, by this study, we even support the fact that ions play just as important role as $\mathrm{K}^{+}$ions along with $\mathrm{Na}^{2+}$ ions in maintaining normal conductivity and contractility of muscles. As we know, $\mathrm{Na}^{2+}$ ions, $\mathrm{K}^{+}$are very important for the depolarization and repolarization of the nerves and to maintain the normal contraction of the muscles, in the current study we saw a patient to whom a diet rich in these ions showed a and a rapid increase muscle strength and have also shown an improvement in functional independence while others who have been deprived of ionic correction and who have just been followed up with only pharmacological therapy combined with conventional physiotherapy have just shown a drastic drop of its capabilities due to a sudden drop in the content of these ions, so it is evident that these ions play a major role in maintaining and improving d Sensory motor skills, helping them recover their func- 
tional abilities at a faster rate The recommended dose of potassium per day is 4.7 $\mathrm{g}$ according to the Linus Pauling Institute at Ohio State University. Oranges are a good source of potassium, providing $237 \mathrm{mg}$ each and 6 ounces. Serving of orange juice provides $372 \mathrm{mg}$, according to the Linus Pauling Institute. This is about $5 \%$ of the $4.7 \mathrm{~g}$ of potassium per day recommended for most people. 1 medium-sized potato contains $925.6 \mathrm{mg}$ of potassium. According to the US Food and Drug Administration, 1 banana contains $450 \mathrm{mg}$ of potassium. banana We have advised for the case of taking daily, 1 or 2 oranges which constitutes-237 - $474 \mathrm{mg} \mathrm{K}^{+} /$day 1 or 2 potatoes-925.6 - $1851.2 \mathrm{mg} \mathrm{K}^{+} /$day 2 - 3 bananas-900 - $1350 \mathrm{mg} \mathrm{K} /$ day According to the US Food And Drug Administration, the salt limit for people without hypertension is 2300 milligrams per day and the limit for people with hypertension is 1500 milligrams per day. An ultra-low-salt food is considered to be a food containing less than 35 milligrams of sodium per serving, according to the United States Food and Drug Administration. We advised the case to eat $1500 \mathrm{mg}$ of salt per day in addition to the small amounts of salt naturally present in foods generally consumed while the witness is deprived of salt. The salt contains $\mathrm{Na}^{2+}, \mathrm{Cl}^{-}$ions. The World Health Organization recommends that adults consume less than $2000 \mathrm{mg}$ of sodium (contained in $5 \mathrm{~g}$ of salt) per day. US guidelines recommend that people with hypertension, African Americans, and middle-aged and older adults limit their intake to a maximum of $1500 \mathrm{mg}$ of sodium per day and adhere to the potassium recommendation, of $4700 \mathrm{mg} /$ day with a healthy diet of fruits and vegetables. This study specifically showed how these ions are globally responsible for the neurological recovery and well-being of one patient while the other patient worsens due to the deficiency or fall of these ions at the crucial stage of recovery.

\section{Conclusion}

Thus, the results obtained from the data collected and analyzed in the 2 subjects clearly show that the ionic balance by diet correction associated with physiotherapy is more effective than conventional physiotherapy associated with pharmacological management. Diet is the best natural alternative to correcting ionic deficiencies than drugs and it has better absorption in the body without side effects.

\section{Acknowledgements}

We thank all who participated in the study.

\section{Author's Contributions}

CG, DKN and ANN designed and analyzed the statistical data for the study. AD, GBM, GMM, SA, KSA and AAP supervised the study. All authors have read and approved the final and revised version of the manuscript.

\section{Conflicts of Interest}

The authors declare no conflicts of interest regarding the publication of this paper. 


\section{References}

[1] Recommandation de bonne pratique (2012) Accident vasculaire cérébral: Méthode de rééducation de la fonction motrice chez l'adulte. HAS.

[2] Clarkson, A.N. et al. (2010) Reducing Excessive GABA-Mediated Tonic Inhibition Promotes Functional Recovery after Stroke. Nature, 468, 305-309. https://doi.org/10.1038/nature09511

[3] Stinear, C., Ackerley, S. and Byblow, W. (2013) Rehabilitation Is Initiated Early after Stroke, but Most Motor Rehabilitation Trials Are Not: A Systematic Review. Stroke, 44, 2039-2045. https://doi.org/10.1161/STROKEAHA.113.000968

[4] Lohse, K.R., Lang, C.E. and Boyd, L.A. (2014) Is More Better? Using Metadata to Explore Dose-Response Relationships in Stroke Rehabilitation. Stroke, 45, 2053-2058. https://doi.org/10.1161/STROKEAHA.114.004695

[5] De Perreti, C. and Woimant, F. (2010) Le handicap consécutif aux accidents vasculaires cérébraux dans la population des ménages ordinaires. Institut du Veille Sanitaire.

[6] Deroide, N., Nih, L.R., Tran Dinha, R.Y., Lévya, B. and Kubisa, N. (2010) Plasticité cérébrale: De la théorie à la pratique dans le traitement de l'accident vasculaire cérébral. La Revue de Médecine Interne, 31, 486-492. https://doi.org/10.1016/j.revmed.2009.08.014

[7] Jauch, E.C., et al. (2013) Guidelines for the Early Management of Patients with Acute Ischemic Stroke: A Guideline for Healthcare Professionals from the American Heart Association/American Stroke Association. Stroke, 44, 870-947. https://doi.org/10.1161/STR.0b013e318284056a

[8] Fery-Lemonnier, E. (2009) La prévention et la prise en charge des accidents vasculaires cérébraux en France. Rapport à Madame la ministre de la santé et des sports. Paris.

[9] FIM Instrument@ Copyright 1997 Uniform Data System for Medical Rehabilitation, 1997.

[10] Kendall, F.P. (1993) Manual Muscle Testing Procedures.

[11] Blumenfeld, H. (2010) Neuroanatomy Trough Clinical Cases. $2^{\text {nd }}$ Edition.

[12] Romito, K. (2019) Minerals: Their Functions and Sources-Michigan Medicine. http://ww.uofmhealth.org/health-library/ta3912 